\title{
Groups discipline resource use under scarcity
}

\author{
Florian Diekert $^{1,2}$ (D) Kjell Arne Brekke $^{3}$
}

Accepted: 29 March 2021 / Published online: 13 April 2021

(C) The Author(s) 2021

\begin{abstract}
Scarcity sharpens the conflict between short term gains and long term sustainability. Psychological research documents that decision makers focus on immediate needs under scarcity and use available resources more effectively. However, decision makers also borrow too much from future resources and overall performance decreases as a consequence. Using an online experiment, we study how scarcity affects borrowing decisions in groups. We first document that scarcity affects groups in a similar way as individuals. Then, we go on to show that the negative effect of scarcity is weaker for groups than for individuals. Even in a minimal design that excludes direct interaction or communication, the fact that participants know that their own behavior affects and can be partly observed by another participant disciplines their use of scarce resources. Our results thus highlight the benefit of groups as units of human organization.
\end{abstract}

Keywords Group behavior - Scarcity · Psychological effects of poverty · Selfcontrol

\section{Introduction}

Scarcity means that available resources are insufficient to meet the needs. During a drought, farmers have to decide which plots to water and which plots to give up. In times of financial stress, firms and households have to decide which bills to pay or which creditors to serve first, and under time pressure only some tasks can be completed while others have to be dropped. Mullainathan and Shafir (2013) argue that scarcity changes the way humans think and act: It puts us in a specific state of mind where we tend to focus narrowly at the most urgent needs and neglect other,

Florian Diekert

diekert@uni-heidelberg.de

1 Alfred Weber Institute for Economics, Heidelberg University, Heidelberg, Germany

2 CEES, Department of Biosciences, University of Oslo, Oslo, Norway

3 Department of Economics, University of Oslo, Oslo, Norway 
equally important but less pressing, needs. They call this state of mind "tunneling". In this paper, we ask whether groups "tunnel" to the same extent as individuals.

Tunneling affects the allocation of resources between more pressing and less pressing projects, ${ }^{1}$ highlighting the double-edged nature of scarcity: On the one hand, scarcity increases focus and available resources are used more effectively (Shah et al. 2012; Gabaix 2019). Most readers can probably relate to that a pressing deadline can lead to significant improvements in short-term productivity (Kurtz 2008). Rational inattention theories predict that decision quality improves with scarcity (Sims 2003). Indeed, using data from a randomized controlled trial among small-scale farmers in Zambia, Fehr et al. (2019) show, for example, that the endowment effect decreases under scarcity.

On the other other hand, scarcity-induced focus comes at a cost. Tunneling means that decision makers lose oversight and neglect important, but less pressing, long-term projects. For example, Laajaj (2017) shows that an exogenous relief of financial scarcity leads to longer planning horizons among poor (but not among wealthy) maize farmers in Mozambique. Neglect of issues that are not in the immediate focus may also be a result of finite mental resources. Building on this idea, Spears (2011) points out how depleted willpower is associated with economic decisions for the poor, but not for the rich. Similarly, Mani et al. (2013) show that financial scarcity negatively affects cognitive performance, both in the lab and in the field. In fact, already the uncertainty about a future shortage of rainfall can lead to significant behavioral biases (Lichand and Mani 2016).

In sum, tunneling may be a mechanism that allows us to push through dire straits, but over time, it may lead into a psychological poverty trap (Haushofer and Fehr 2014). So far, the literature has analyzed individual behavior. Here, we study how scarcity affects decisions in groups. Do groups neglect long-term projects under scarcity to the same extent as individuals do? Groups and teams are a basic unit of human organization, and in many developing countries natural resources that are prone to fluctuations and periods of acute scarcity, such as groundwater, grazing lands, or fisheries, are owned or used collectively. Do groups also borrow in order to meet the needs of the present, and thereby compromise the ability to meet their needs in the future?

Our study is based on the design of Shah et al. (2012), where participants solve a series of tasks within a given time budget, which is either abundant or scarce. To solve the current task they can borrow time from future tasks. This is exactly the tradeoff between the here and now task versus equally important future tasks. Even if such borrowing is harmful for overall performance, participants do borrow when time is scarce but not when it is abundant. As a consequence, participants' overall performance is worse under scarcity than under abundance.

A number of previous experiments use exogenous time pressure to study decisions. ${ }^{2}$ Importantly, several studies that analyze whether cooperating in social

\footnotetext{
1 This is different from discounting, which generally discriminates between projects based on their order in time.

2 An early contribution to the literature that studies response times is (Piovesan and Wengström 2009). Spiliopoulos and Ortmann (2018) provide a recent review of the field.
} 
dilemmas is fast and intuitive, or slow and deliberate, use tight time budgets to induce fast decisions (Rand et al. 2012; Rand 2016; Tinghög et al. 2013; Bouwmeester et al. 2017; Brozyna et al. 2018). Our study differs from this literature because we are not asking whether decisions that are taken under a tight time constraint are different from decisions when time is abundant, but we study the effect of time scarcity on time management as such. Specifically, our focus is on the effect of "tunneling". Does scarcity increase focus on the immediate task while neglecting long-term consequences also for groups?

On the one hand, research has shown that groups are better at self-control than individuals (Kugler et al. 2012; Charness and Sutter 2012). Excessive borrowing may be seen as an issue of self-control. If the mechanism is that scarcity affects the ability to self-control (Spears 2011), we would expect less borrowing in the group setting than in an individual setting. On the other hand, groups must work together to be successful. If scarcity increases selfishness (Prediger et al. 2014; Roux et al. 2015), we would expect to see more borrowing and lower performance in the group than in an individual setting.

Note that the groups in our setting are rather minimal. They do not work together to solve the sequence of tasks. They are only a group in the sense that they share a joint time budget and are paid by their joint performance. A relevant natural setting with such a structure is a paper that is prepared by two coauthors for a tight conference deadline. Sequential work dictates that the time spent by the first author cannot be used by the second author, and the quality of the paper may diminish when the first author takes too long such that the second author has only very little time left to work on the manuscript. On the other hand we can also feel more obligation towards a paper with a coauthor, which can make us better at meeting the tight deadline when we have a coauthor.

Sequential work characterizes many production processes and time is generally a valuable resource. Parallel to the poor borrowing money that costs interest, the busy borrow time by taking extensions. And similarly to banking money, finishing a task earlier allows spending more time on other tasks. Shah et al. (2012) use these properties of sequential production under a binding time constraint to experimentally investigate whether scarcity leads participants to overborrow. Here, we replicate the findings of Shah et al. (2012). ${ }^{3}$ Further, we recover the average production function in the experimental task. Doing so allows us to pinpoint how tunneling yields a short-term gain in increased productivity in the first seconds at the task, while leading to an overall drop in performance due to harmful borrowing. Our two main results are first that we document that scarcity affects groups in a similar way as individuals and secondly that we show that the negative effect of scarcity is weaker for groups than for individuals.

Our study is pre-registered, and we discuss the pre-registered hypotheses below. While we did know that self-control in groups could have an impact, we did not have specific hypotheses. Thus, parts of the results surprised us; the effect of groups on self-control was stronger than we initially thought. To ensure that this result was not spurious, we ran a follow-up study, with a slightly altered design and with the

\footnotetext{
3 The original instructions and computer codes were generously provided to us by Anuj Shah.
} 
effect in question pre-registered. The results in the follow-up study were corrupted by an unfortunate comment on the MTurk message board, and the conclusion remained unclear. We thus collected a new sample outside of MTurk, which gives some support to our initial results. As the follow-up studies are motivated by the first study, we present each study and the main results consecutively. ${ }^{4}$

\section{Main study}

The aim of our main study is to test whether scarcity leads to "tunneling" for individuals that are in groups, and whether this effect differs compared to individuals that are alone. Specifically, we aim to investigate time use, borrowing decisions, and performance of participants when solving a sequence of tasks under a given time budget.

\subsection{Design}

Shah et al. (2012) found similar results across different designs, so we start with the original design of one of their studies, where participants perform an online task. The task is modeled after the TV-show "Family Feud": Participants are faced with a question (for example, name things that you take on a picnic) and have to guess which answers were most popular among a random sample of 100 people. Participants earn one point per correct answer, but they only have a limited amount of time per question. (Points are later exchanged into real money, 1 point=0.05 USD on MTurk or 1 point $=3$ NOK in Oslo.) There are twelve rounds with one question each in our version of the game. ${ }^{5}$

Our design is based on their basic design, with treatments organized as $2 \times 2$ with an extension. The first dimension is the time budget. Under conditions of abundance, participants have a large time budget to answer questions (50 s per question). Under scarcity, participants have a tight time budget (15 s per question). Participants answer questions for up to twelve rounds in total, and they can transfer time between rounds. They can end a round early and thereby "bank" time for future rounds, or they can spend more than the allotted time in a given round and "borrow" time from future rounds. To move from one round to the next, players must press a "Next round" button on the right margin of the screen (see Appendix A.5 for screen shots and more details on the game mechanics). As in Shah et al. (2012), borrowing is costly. Using $1 \mathrm{~s}$ in excess of the allotted time budget per question reduces the available total time budget to answer later questions by $2 \mathrm{~s}$.

The second dimension is how the time budget is shared. In all treatments participants are matched randomly and anonymously in pairs, and their earning is proportional to the total score of the two players in the pair. In treatments with

\footnotetext{
${ }^{4}$ The AER registry link for the main study is: https://doi.org/10.1257/rct.2582-3.0.. For the follow-up study, it is: https://doi.org/10.1257/rct.4061-3.0..

${ }^{5}$ In Shah et al. (2012), there were 20 rounds so that players had 300 and $1000 \mathrm{~s}$ in total (but same amount per question).
} 
individual time budget, the game ends when a given player has exhausted her own time budget. When time budgets are joint, we order participants in sequence such that one participant plays first and the other second. The first player can exceed her own allocated time and borrow from the second player but not vice versa. Note that there is no income externality as players are paid according to their joint score: the first player cannot gain at the expense of the second player, by borrowing. Borrowing decreases the time that the second player has available and may thus directly harm the first player's payoff. In this way, both effective time use and more effort to increase payoff is as good for the player herself as for her partner.

This $2 \times 2$ design leaves us with four treatments: Individual abundant time budget (IA), individual scarce budget (IS), joint abundant time budget (JA), and joint scarce budget (JS). The comparison of the treatment with an individual abundant time budget (IA) to the treatment with an individual scarce budget (IS) can be used to replicate the borrowing treatment in the fourth experiment of Shah et al. (2012). Comparing the treatment with a joint abundant time budget (JA) to the treatment with a joint scarce budget (JS) gives the effect of scarcity on groups.

As we expect borrowing to be harmful, IS groups may perform better than the JS groups, simply because the respective first players in the IS treatment cannot spend from the time budget of her partner. To disentagle the effect of having a partner from the mere possibility of inefficient borrowing, we therefore use a fifth treatment where participants are matched with a virtual second player (VSP). Except for the second player being virtual, the treatment is identical to the JS treatment. Players in the VSP treatment have the same $15 \mathrm{~s}$ per round and the same overdraft budget as the first players in the JS treatment, but their payoff is calculated as a function of the time that they leave behind for the (virtual) second player. In this treatment the expected loss of earnings from spending from the partners time budget is the same as in the JS treatment, thus any difference between the two must be due to the effect of having a real partner.

\subsection{Results}

The experiment was conducted between January 5, 2018 and January 10, 2018. Participants were recruited via Amazon's mechanical turk platform. We have obtained 752 valid observations ${ }^{6}$ that are distributed over the four different treatments as follows: 109 participants in the IA treatment, 114 participants in the IS treatment, 217 participants in the JA treatment, 205 participants in the JS treatment, and finally 107 participants in the VSP treatment.

On average, participants spent $12.2 \mathrm{~min}$ for the entire experiment $($ minimum $=$ $3.5 \mathrm{~min}$ and maximum $=32 \mathrm{~min}$ ). Table 1 gives an overview of the sample demographics. Of the 752 participants in the sample, 412 are female (i.e. 55\%).

\footnotetext{
6 The survey website was visited by 929 potential participants and 804 started the first round of the game, after having read the instructions and completing three practice rounds. Of these, 36 dropped out during the game, at least 8 because they attempted to re-load the page against explicit advice (by a pop-up window). 766 participants completed the game, but 14 observations had to be deleted because the variables were incorrectly or incompletely recorded due to technical errors. Thus, we are left with 752 valid observations.
} 
Table 1 Summary statistics of sample demographics

\begin{tabular}{lllll}
\hline Statistic & Mean & St.dev. & Min & Max \\
\hline Age & 36.79 & 10.96 & 18 & 73 \\
Gender (male =0) & 0.55 & & 0 & 1 \\
Education & 2.60 & 0.95 & 0 & 5 \\
Know Family Feud & 0.94 & & 0 & 1 \\
\hline
\end{tabular}

Education is measured as a factor with six different levels ${ }^{7}$ and a Bachelor degree is the modal response. Importantly, 94\% of the participants in the sample answered that they know the game show Family Feud.

We present our results in two steps. Before comparing the behavior of players that are in a group with those that are alone, we first document the effect of scarcity. Replicating the finding of Shah et al. (2012) and showing that it also holds for groups establishes that our experiment is indeed informative on cooperation under scarcity.

We are particularly interested in the behavior of the first player because it is this player that may or may not borrow from a partner in the joint treatments. Therefore, we use the scoring rule to account for the points of the second player when reporting performance. This makes the results comparable across treatments, and it reduces the noise generated by variable skills and guessing by second players. Similarly, we concentrate on the first players when reporting time use over different rounds. We say that players are in a group when their time budget is connected with another participant's time budget (JA and JS treatments), and we say that players are alone when their time budget is not connected with another participant's time budget (IA, IS, and VSP treatments).

\subsubsection{Scarcity decreases performance and increases borrowing}

Performance under scarcity is lower than performance under abundance, as shown in Fig. 1a. The difference between abundance and scarcity is highly significant, as shown in Appendix A.2. While this difference is not surprising, it is important to note the following: Under abundance players are net savers, but they borrow under scarcity (Fig. 1b). Thus, borrowing is induced by scarcity and not a consequence of how the game is set up. With abundant time resources, players manage to both focus on the task and keep track of time. In this case the possibility to borrow from the partner does not harm performance. When time resources are scarce, however, players have to focus on the main task. This "tunneling" causes a neglect of time. This also indicates that time really is abundant with $50 \mathrm{~s}$ per question but scarce with only $15 \mathrm{~s}$ per question.

In short, we see that scarcity causes more borrowing. Hence, we turn to the effect of borrowing and the difference between the different treatments under scarcity.

\footnotetext{
7 The variable was coded as follows: $0=$ "not completed highschool"; 1 = "highschool"; 2 = "some college"; 3 = "bachelor"; 4 = "master"; 5 = "phd".
} 


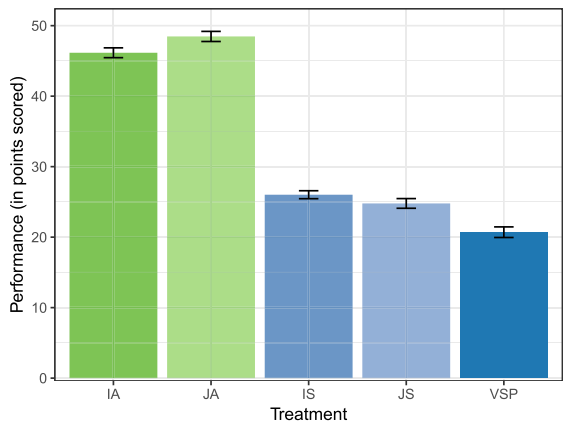

(a) Performance.

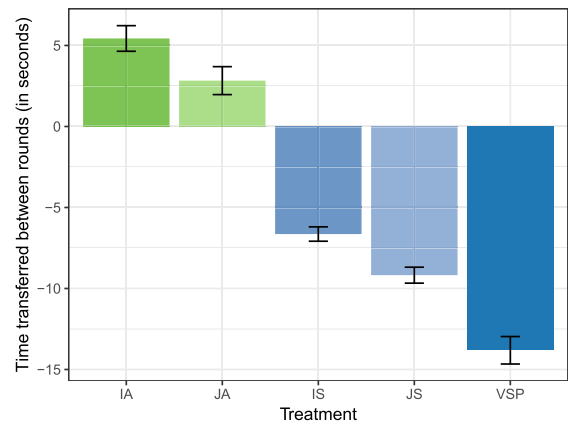

(b) Time transfer

Fig. 1 Performance and Time transfers under abundance (green) and scarcity (blue). Performance is based on the behavior of first players with a common scoring rule for second players. The average amount of time that is transferred (positive or negative, excluding interest rate payments) from one round to the next also includes transfers to the next player with joint time budget. Errorbars show $\pm 1 \mathrm{SE}$

\subsubsection{Borrowing is bad for performance}

There are two reasons why borrowing is harmful: First, because there are decreasing marginal returns to working at the task (the production function is concave). Second, because there is a $100 \%$ interest rate on borrowed time.

The 100\% interest rate means that even with constant returns (a linear production function), a player must be twice as good in answering a given question as in answering later questions, in order to justify taking time from the budget available for answering later questions. In particular, the player must be twice as good as the partner to justify borrowing from the partners' time budget. With a concave production function (decreasing marginal returns), it is not even sufficient to be twice as productive to justify borrowing from a partner. As it turns out, the best ideas for answering a given question are usually exhausted quickly.

To document the production function, we have recorded the time at which a player has scored a point. Using this, we can construct the average number of points that players score as a function of the elapsed time in a given round. The results are shown in Fig. 2, illustrating the concavity of the production function. Clearly, spending another second at the task when $5 \mathrm{~s}$ have elapsed yields a much higher return (in terms of expected points) than spending another second when $20 \mathrm{~s}$ have elapsed.

This analysis also allows us to illustrate the positive effect of tunneling: In the beginning, the production function in the scarcity treatments is clearly above the corresponding function of the abundant treatments. In the first $10 \mathrm{~s}$ of a given round, players under scarcity score 1.29 points $(s d=0.77)$ on average, while they score 1.07 points $(\mathrm{sd}=0.83)$ under abundance. The difference is highly significant $(p<0.001$ for all comparisons). That is, scarcity induces players to use their resources more effectively in the short run. This is the "focus dividend" (Mullainathan and Shafir 2013). However, this increase in focus comes at a cost: Under scarcity, players tunnel and do not consider the negative effect of borrowing. 


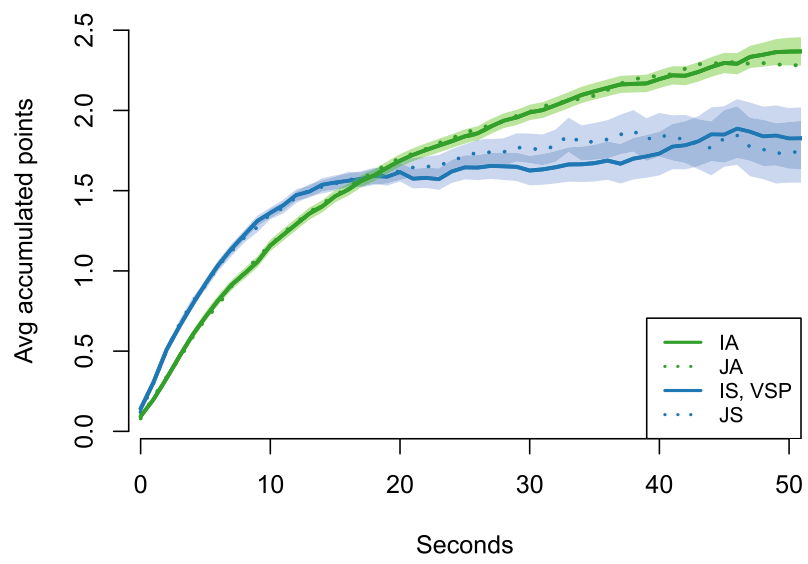

Fig. 2 Average accumulated points as a function of time used in a given round. Shaded areas visualize the $99 \%$ confidence bands

Because using more time beyond the given initial time has strongly decreasing returns, it is bad for performance.

\subsubsection{Groups borrow less under scarcity}

Having established that scarcity induces tunneling also when players are matched in groups, we now turn to comparing the behavior of players that are alone under scarcity to the behavior of players that are in a group under scarcity. To this end, it is important to recall that the IS treatment is not a valid counterfactual for the behavior of players under the joint time budget. Here, the first players of a group could borrow more, simply because they can. Thus, the relevant control treatment is the VSP treatment, where players have the same overdraft budget as in the JS treatment, but they are not matched with a real second player. In the following, we therefore concentrate on these two treatments.

Comparing the average time transfer across rounds in the JS treatment with the time transfer in the VSP treatment (the two rightmost bars in Fig. 1b), we see that players in groups borrow $9.2 \mathrm{~s}$ on average from future rounds, while players that are alone borrow $13.8 \mathrm{~s}$. This difference is modest $(d=0.35)$ but strongly significant $(p=0.007)$.

The fact that groups borrow less under scarcity is confirmed in a regression analysis of overall borrowing on the treatment (using only the data from the JS and the VSP treatment). Column 1 in Table 2 shows that players that are matched with a real second player (JS treatment) borrow, in total over all twelve rounds, $19.8 \mathrm{~s}$ less in total than players matched with a virtual second player. This effect is strongly significant $(p=0.002)$. With respect to the control variables, we see that there is a gender effect and that a higher education level is correlated with less overall borrowing. Similarly, younger players and those that know the game "Family Feud" tend to borrow less. 
Table 2 OLS regression results using data from the first players of the JS and VSP treatment

\begin{tabular}{llll}
\hline & \multicolumn{2}{l}{ Dependent variable } & \\
\cline { 2 - 4 } & Borrowing & Performance & $(3)$ \\
\cline { 2 - 3 } & $(1)$ & $(2)$ & $2.381^{* * *}(0.732)$ \\
Group & $-19.784^{* * *}(6.358)$ & $4.521^{* * *}(0.991)$ & $-0.108^{* * *}(0.008)$ \\
Borrowing & & & $1.295^{*}(0.743)$ \\
Female & $15.819^{* *}(6.512)$ & $-0.417(1.015)$ & $5.369^{* * *}(1.420)$ \\
KnowFF & $-25.920^{* *}(12.498)$ & $8.173^{* * *}(1.948)$ & $0.012(0.034)$ \\
Age & $0.815^{* * *}(0.298)$ & $-0.077(0.046)$ & $0.176(0.385)$ \\
Education & $-6.176^{*}(3.391)$ & $0.844(0.529)$ & $21.830^{* * *}(2.289)$ \\
Constant & $75.048^{* * *}(19.663)$ & $13.712^{* * *}(3.065)$ & 212 \\
Observations & 212 & 212 & 0.551 \\
Adjusted R & & 0.138 & 5.148 \\
Residual std. error & 45.769 & 7.134 & $44.167^{* * *}$ \\
F statistic & $6.266^{* * *}$ & $7.758^{* * *}$ & \\
\hline Performance in & & &
\end{tabular}

Performance is the score of the first player plus the a computed score for the second player using the same rule as in VSP. The variable Group is a dummy that takes a value of 1 if the observation is from the JS treatment. Female and KnowFF are dummy variables taking a value of 1 when the participant is female or knows the game "Family Feud"

Standard errors in parantheses; $* p<0.1 ; * * p<0.05 ; * * * p<0.01$

In the next part, we discuss how borrowing less translates into better performance.

\subsubsection{Groups perform better under scarcity}

Figure 1a shows that players in groups (JS) score about four points more than players that are alone (VSP). This difference is strongly significant $(p<0.001)$. In other words, being in a group under scarcity translates into an increase in performance of about $20 \%$.

This result is strengthened when controlling for observable co-variates in the regression analysis (column 2 of Table 2). The estimate of the direct effect of being in a group on performance is then 4.5 points. In comparison to the analysis of borrowing, the regression shows that gender, age, and education play no role in explaining performance, while knowledge of the game "Family feud" is a good predictor of better performance.

The clear evidence of the decreasing marginal returns to spending additional time on the task (Fig. 2) strongly suggests that groups perform better under scarcity because they refrain from borrowing to a larger extent than individuals. Additional support that the increase in performance is indeed related to the observed differences in borrowing behavior comes from a mediation analysis (Hayes 2013). As it can be seen in column 3 of Table 2, the point estimate of the effect of being on 
a group on performance decreases to 2.3 points while the effect of borrowing on performance is negative and strongly significant. This means that there is strong evidence for a partial mediation (Sobel test, $p=0.003$ ). Almost half of the effect of being in a group works via the indirect channel of borrowing on performance.

\subsection{Discussion of the main study}

Shah et al. (2012) study the effect of poverty on resource management decisions and show that with scarce time to solve a task, participants borrow time from future tasks at a high interest rate. This is harmful for their overall performance and earnings in the experiment. We use the same basic design, but with two players sharing a joint time budget. Our results corroborate these claims; Participants do much more of the harmful borrowing when their time budget is scarce-compared to abundant. Our data highlights some additional features: under time scarcity participants are much more productive in the first few seconds-thus the narrow focus of tunneling has its benefit. We also show that the production function is strongly concave, which further speaks for the inefficiency of borrowing.

The focus of our main study was the extent to which tunneling would also be harmful for cooperation in groups. To study this, we matched participants in pairs and indeed found that participants under scarcity do borrow time from their partners' time budget. Given the very high interest rate and the strongly concave production function, this should be harmful for the joint performance of the group. Note that we did not study how scarcity affects (non-)cooperation in terms of increasing free-riding, as both participants in a group had a common interest and were paid according to their joint score. The question was if the narrow focus due to tunneling also causes a neglect of the group partner, which it apparently does.

There could be several underlying factors that may give rise to this result. First, we conjectured in the pre-analysis plan that borrowing from others could be linked to confidence and over-confidence. In particular, we expected that first players who believe that they are better than the average (confidence) would borrow more. Fifty out of 105 first players in the JS treatment think that they are better than the average player in their treatment. Although these players do borrow more than players that believe that they are equal or worse than the average $(60.8 \mathrm{~s}, \mathrm{SE}=5.99$, versus 49.2 $\mathrm{s}, \mathrm{SE}=6.22$ ), the difference is not significant. ${ }^{8}$ When we look at the effect of overconfidence, we find that first players that believe they are better than they actually are borrow $74.1 \mathrm{~s}$ on average $(\mathrm{SE}=6.19)$, and first players that believe they are worse than they actually are borrow $50.5 \mathrm{~s}$ on average $(\mathrm{SE}=5.47)$. This effect is strongly significant $(p<0.001)$. Interestingly, we find that $65 \%$ of all players that were subject to either the individual or the joint scarcity treatment believed that they were better than they actually were, while this is true for only $45 \%$ of the players in the abundance treatments $(p<0.001)$. While these findings are in line with the studies that suggest that scarcity induces a more agentic orientation (Roux et al.

\footnotetext{
${ }^{8}$ Note that the fact that this measure does not show up as an important explanatory variable is in line with the idea of tunneling, which exactly says that participants do not make conscious, rational decisions on borrowing under scarcity.
} 
2015), they cannot explain the differences between groups and individuals given scarcity.

Second, concern for others could mean that players are more motivated to work hard and perform well in the group treatment. Considering the mechanism that players exert more effort, we find that first players in the JS treatment make 38.3 guesses over the entire task on average ( $\mathrm{SE}=1.21$ ), while players in the VSP treatment make 34.7 total guesses on average $(\mathrm{SE}=1.51)$. Although the finding is not strongly significant $(p=0.06)$, it points in the direction that concern for other players induces more effort.

Finally, being in a group could affect self-control, which is important because it is clearly sub-optimal to borrow from the partner. To illustrate, consider a player who borrows the maximum amount feasible from a partner, but spreads the available time evenly. This player can spend $16.8 \mathrm{~s}$ per round instead of $15 \mathrm{~s}$ per round. ${ }^{9}$ The additional $1.8 \mathrm{~s}$ do little for the overall score, as seen from Fig. 2, but it reduces the score from the second player substantially.

Given how inefficient it is to borrow from the partner, it is striking that the performance in the JS treatment is not significantly worse than in the IS treatment (24.8 versus 26 points, $p=0.16)$. In the VSP treatment, however, performance drops significantly compared to IS and JS $(p<0.001)$. What makes this even more surprising is that players in the VSP treatment do not take that much more time in total from the overdraft budget than players in JS treatment; $33 \mathrm{~s}$ versus $25 \mathrm{~s}$ $(p=0.03)$.

Upon closer inspection, we find that where the players that are alone really stand out, is in borrowing in the early rounds. Figure 3 offers a closer look at the borrowing behavior between rounds. The panel on the left shows the time that is transferred (taken) from upcoming rounds in the early phase of the game (rounds $1-4)$. The panel on the right shows the time that is borrowed in the late phase of the game (rounds 8-12). In the JS and the VSP treatment this includes the time taken from partner's time budget (real or virtual), while in the IS treatment, it was not possible to extend the initial time budget.

There is little difference between players that are alone and players in a group in rounds $8-12$, but there is a clear and strongly significant difference between players that are alone and groups in the early rounds. ${ }^{10}$ Players that share a joint time budget with a real player manage their time much better than players in the VSP treatment. In fact, the point estimate of the average time transferred in the early rounds in the JS treatment is even lower than the average time transferred in the IS treatment 8.0 ( $\mathrm{sd}=19.6)$ versus $9.6(\mathrm{sd}=20.2)$ seconds, though this effect is not significant, $p=0.45)$.

One possible explanation for this result is that a real partner enhances selfcontrol, and thus causes first player to manage their time better than without a real

\footnotetext{
9 Note that while the first player can take $120 \mathrm{~s}$ from the partner's budget, his own time increases only $21.4 \mathrm{~s}$ due to $100 \%$ interest rate and compound interest.

${ }^{10}$ Average borrowing across rounds in the JS treatment for periods 8 to 12 is $10.9(\mathrm{sd}=15.5)$ and 11.9 $(\mathrm{sd}=16.1)$ in the VSP treatment $(p=0.54)$. For rounds $1-4$, we have an average borrowing across rounds of $8.0(\mathrm{sd}=19.6)$ in the JS treatment and $16.8(\mathrm{sd}=38.6)$ in the VSP treatment. The $p$-value here is 0.002 and Cohen's $d=0.61$.
} 


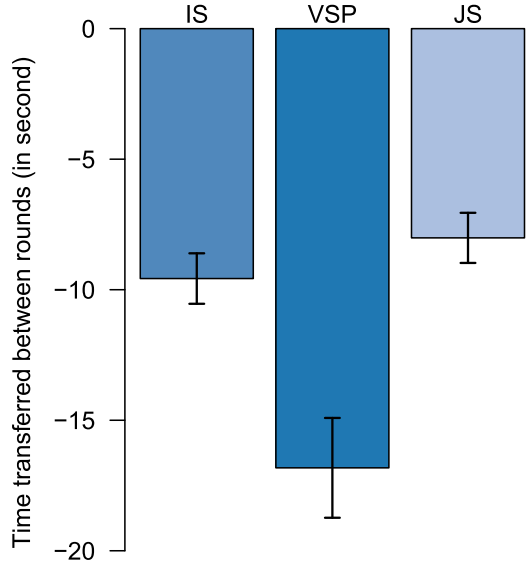

(a) Early rounds (R1-R4)

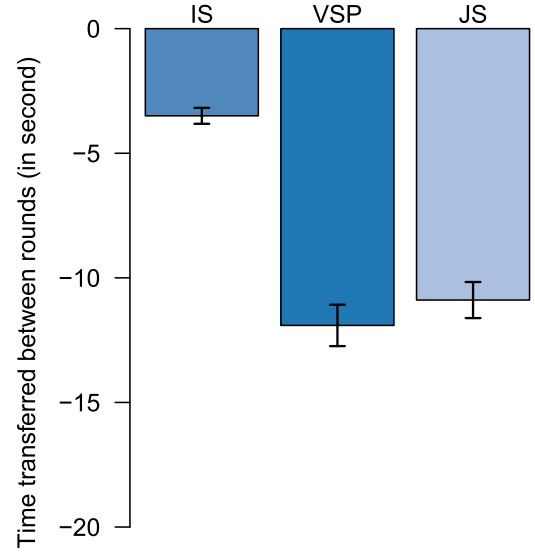

(b) Late rounds (R8-R12)

Fig. 3 Time use under scarcity in early and late rounds. Errorbars show $\pm 1 \mathrm{SE}$

partner. However, we had no hypotheses about borrowing in the first four rounds, increasing the likelihood that the result is spurious. Thus, we ran a new study to test this specifically.

\section{Follow-up study}

The results from our main study indicate that groups have an impact on self-control that we did not anticipate in our pre-study plan. This could be because the first player believes that the second player to some extent observes the first players' action (as the second player gets a residual time budget that depends on the first players' actions). A second effect could be that social preferences induce more selfcontrol in the first players as they know that both players get the same payoff.

To disentangle these effects, we developed a $2 \times 2$ design varying observability and being in a pair versus alone, based on the treatments JS and VSP from the main study. An alone (A) player had no partner, as in the VSP treatment, while in a pair (P) the second player was real. With no observability (NO) we gave no information about what the second player would learn, while under observability (O) we added a statement in the instructions stating that "Your partner [A player entering the game after you] will learn about your borrowing as well as your total score." (The text in brackets was used when the player had no real partner.) This leaves us with four treatments: ANO, AO, PNO, and PO.

In the following, we describe the results from a first sample from Amazon MTurk, and then-because we have reasons to believe that these results are not trustworthy - the outcome of a second sample, recruited from the University of Oslo. 


\subsection{MTurk sample}

The experiment was conducted on May 9-10 and June 3-18, 2019. Participants were recruited via Amazon's mechanical turk platform. We have obtained 1258 valid observations, of which 768 are from first players. These first players are distributed over the four different treatments as follows: 202 in the AO treatment, 175 in the ANO treatment, 192 in the AO treatment, 192 participants in the PNO treatment, and 199 participants in the PO treatment. Table 3 shows the summary statistics of the sample's demographic variables. With the exception of education level, the differences between the sample in the main study are significant, but small (the average age is about 1 year younger, the share of female participants is about $10 \%$ lower, and the share of participants that know the game show "Family Feud" is $3 \%$ lower).

The main outcome variable in the second study is borrowing in the first four rounds. The results in Fig. 4 show small differences in time transfers between treatments, with no difference being significant. Looking at borrowing in rounds 1-4 from both the main study and this sample, there is only one treatment that stands out: In the main study, JS subjects borrowed $8 \mathrm{~s}$ on average, while in the VSP treatment and in all treatments here, borrowing was around 13-17 s. If having a real partner or being observed drives the result from the main study, then we should see similar low savings in the PO treatment of the follow-up study, but we do not.

One possible explanation is simply that the early borrowing behavior in the main study was spurious. There are, however, many aspect of this follow-up study that make us question the validity of its results. One important concern we had was a message that was posted on the MTurk message board. The message read: "Fun game. Bonus includes your points and your partners, my bonus for my HIT only includes mine as the rest is calculated." The message thus indicates that the partner score is calculated as with a virtual second player. As many MTurkers do this for a living, it is not unlikely that they actively seek out information about a job before accepting it and thus most participants may have read the message before starting. This would undermine the difference between the treatments with real and virtual partners.

To further investigate the impact of the message we looked at data that was collected before the message was posted. In order to test the program and server capacity we ran two small batches of the PO treatment on May 9 and 10, while the main data was collected in June 3-5. As the message was posted on June 3rd, we can only be sure that the observations from May are unaffected. On May 9, the mean borrowing in rounds 1-4 was $7.8 \mathrm{~s}$, while on May 10, the mean was $23.4 \mathrm{~s}$. The means from the two dates are different at any reasonable level of significance. And even though they are from the same treatment, the difference is much larger than the difference between treatments. We do not know why there was such a big difference, but MTurk seems to create large variation between days in our key outcome variable. ${ }^{11}$ In the main study and the principle data-collection for the

\footnotetext{
11 A further indication of the unreliability of the Mturk data in the spring of 2019 is that 2069 potential participants entered the game, but only 1550 completed the practice rounds and 1258 participants
} 
Table 3 Summary statistics of demographics for MTurk sample, follow-up study

\begin{tabular}{lllll}
\hline Statistic & Mean & St. dev. & Min & Max \\
\hline Age & 35.45 & 10.50 & 18 & 81 \\
Gender (male =0) & 0.44 & & 0 & 1 \\
Education & 2.59 & 0.89 & 0 & 5 \\
Know family feud & 0.91 & & 0 & 1 \\
\hline
\end{tabular}

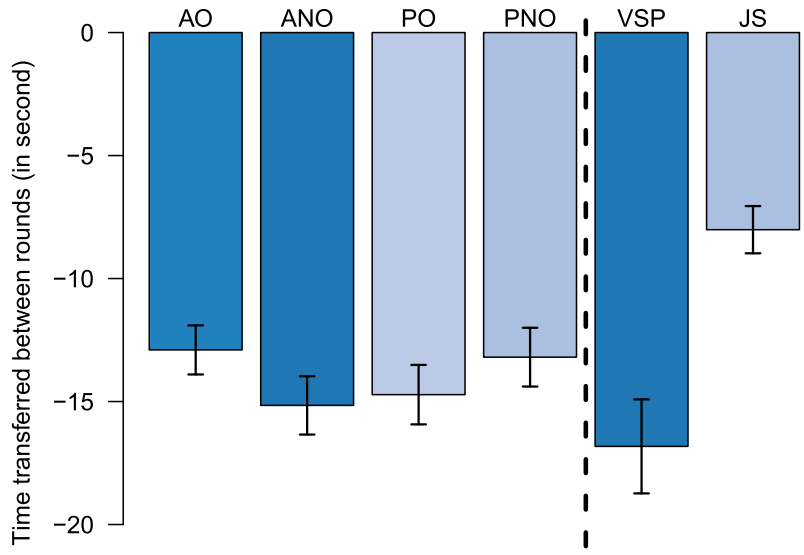

Fig. 4 Time use under scarcity in early rounds, Juxtaposition of follow-up study (Mturk sample, left four bars) and main study (the two right bars). Errorbars show $\pm 1 \mathrm{SE}$

follow-up study in June 2019, participants were randomly allocated to treatments as they entered, and the variation across days should then not be an issue, beyond adding much noise and making estimates less precise.

\subsection{Oslo sample}

As we considered the data from Mturk sample not to be trustworthy, we repeated the follow-up study with a smaller sample recruited among students at the University of Oslo. About a thousand students have signed up to be invited to experiments, but from experience, we expected only a small share to accept the invitation. Due to the expected small sample size, we collected data only for the treatment where subject told that they are with a real partner (Group), and for the treatment with a virtual partner and no observation (Alone). These two treatments allow us to conduct the pre-registered test of the impact of groups on self-control, but not a decomposition between observability and social preferences.

Footnote 11 continued

completed the experiment. The share of participants that completed the experiment to those that started it is $60 \%$ in the follow-up study, while it is $80 \%$ in the main study. Similarly, $144(9 \%)$ of the participants completing the practice rounds refreshed their browser against explicit advice in the follow-up study, while in the main study, only $36(4 \%)$ did so. 
Table 4 Summary statistics of demographics for Oslo sample, follow-up study

\begin{tabular}{lllll}
\hline Statistic & Mean & St. dev. & Min & Max \\
\hline Age & 24.37 & 4.75 & 18 & 53 \\
Gender (male =0) & 0.56 & 0.50 & 0 & 1 \\
Education & 2.91 & 0.89 & 1 & 4 \\
Know family feud & 0.35 & 0.48 & 0 & 1 \\
\hline
\end{tabular}

Table 4 gives the summary statistics of the demographic co-variates of the Oslo sample (collected in two studies, one in December 2019 and a second in October/ November 2020). As can be expected, the typical participant in this sample is significantly younger and better educated than the typical participant recruited via Mturk. Importantly, only about a third of the participants know the game show "Family Feud".

Looking at the time use in the first four rounds, we see that the participants that play alone borrow more than players in a group. Average borrowing across rounds in the group treatment is $14.3 \mathrm{~s}(\mathrm{sd}=30.6)$ and $17.6 \mathrm{~s}(\mathrm{sd}=34.9)$ in the alone treatment. The $p$-value here is 0.39 and Cohen's $d=0.15$. Compared to the main study, the effect of being in a group is hence smaller. Figure 5 illustrates this fact by juxtaposing the time use in the first four rounds of the Oslo sample with the corresponding time use in the main study.

To further analyse the results from the follow-up study in Oslo, we conduct the same regressions as for the main study, shown in Table 5 in the Appendix. We find that those participants that are in a group borrow on average $8.7 \mathrm{~s}$ less in total $(p=0.23)$, and they score 1.8 points more $(p=0.08)$ than participants that play with a virtual partner. While the coefficients all point in the same direction as the coefficients in the main study, they are mostly not significant at conventional levels and often less than half the size as in the main study. In contrast, the negative effect

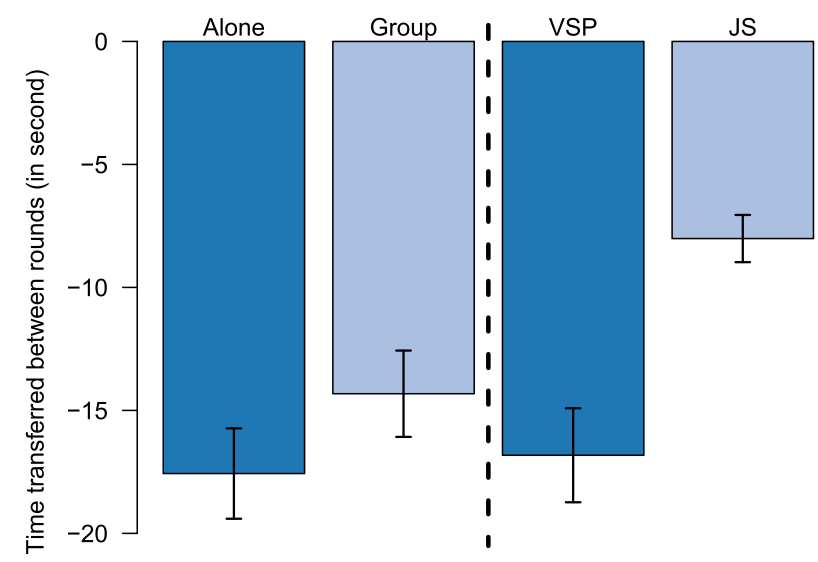

Fig. 5 Time use under scarcity in early rounds. Juxtaposition of follow-up study (Oslo sample, left bars) and main study (right bars). Errorbars show $\pm 1 \mathrm{SE}$ 
of borrowing on performance is highly significant $(p<0.001)$ and about the same size as in the main study.

\subsection{Discussion of the follow-up studies}

The follow-up studies yield inconclusive results: The estimates all point in the same direction as in the main study, but do not reach significance at conventional levels. The reason is that the data on borrowing in the first four rounds is very noisy, and highly sensitive to dropout in the early rounds.

Some participants stop guessing and let the clock run. We do not know why this happens, participants may realize they forgot an appointment or get a phone call, or it can be due to a lack of motivation related to the treatment variable. For the followup study conducted on MTurk, we decided to pre-register a conservative exclusion criteria, excluding only those who did not complete the first round of the main game (after two practice rounds). In the first follow-up study conducted among Norwegian students, we had only one practice round so that the same material criterion translates to excluding participants that drop out within the first two rounds of the main game. Keeping to the formal criterion of excluding participants that drop out in the first round of the main game, the difference between Group and Alone is small and not significant. The reason is that there are two participants in the Group treatment that did not complete round 2. As a dropout means that the player borrows to the max, it has a huge impact on the mean, especially as there are only 34 observations in the Group treatment of the first Oslo study. Excluding participants that drop out within the first two rounds of this study, then yields results that are very similar to those of the main study: Players in groups borrow on average $8.7 \mathrm{~s}$ and $15.9 \mathrm{~s}$ when they are alone $(p=0.08)$.

As a robustness check, we therefore analyze player's time management over all rounds. That is, we estimate a Cox Proportional Hazards model on the time used in a given round (including age, gender, and knowledge of the Family Feud as additional regressors). This analysis tests whether the effect of being group can be detected when making use of the full data.

We find a significant effect of being in a group both in the follow-up study as well as in the main study. Being in a group increases the probability of ending a given round and moving to the next round by $14 \%$ in the Oslo sample and by $34 \%$ in the main study. (Coefficient estimates shown in Table 6 in Appendix A.3) In sum, the effect of being in a group is detectable in the follow-up study as well as in the main study, but it is much larger in the latter study. Figure 6 illustrates this result by plotting the survival curves (the estimated probability to stay in a given round as a function of the time that has passed) for both studies.

\section{Conclusion}

Scarcity means that individuals have to concentrate their resources on the most urgent needs, at the cost of losing sight of the broader picture. Mullainathan and Shafir (2013) call this phenomenon "tunneling". Tunneling may hence be one of the 


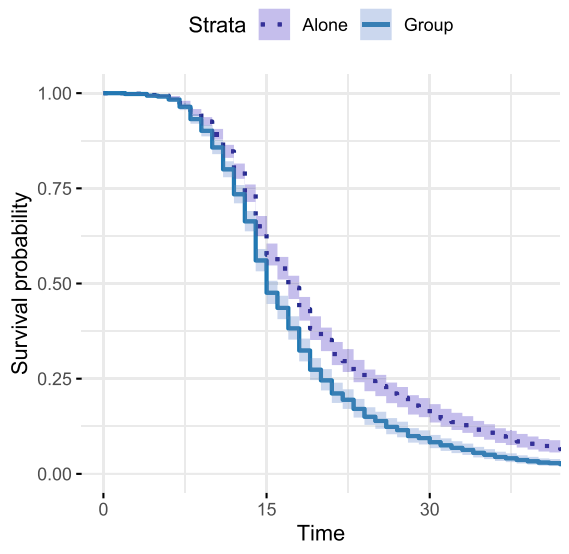

(a) Main study

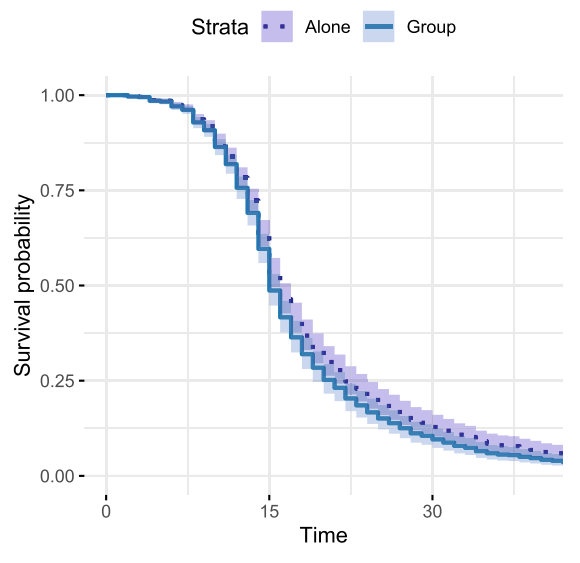

(b) Follow-up Oslo

Fig. 6 Probability to stay in a given round as a function of time spent in round

mechanisms responsible for situations in which "poverty [has] particular psychological consequences that can lead to economic behaviors that make it difficult to escape poverty" (Haushofer and Fehr 2014).

In this paper, we study the extent to which scarcity is harmful for cooperation in groups through the effect of tunneling, excluding - by construction-how scarcity affects free-riding in groups. Replicating Shah et al. (2012), we find that scarcityin contrast to abundance-does induce borrowing. We extend the results of Shah et al. (2012) by showing that the production function is highly concave, making borrowing additionally harmful beyond the effect of the $100 \%$ interest rate. We also find that when first players are allowed to borrow from their partner, they do so. This far our results strongly support a claim that tunneling is harmful for cooperation in group as first players do borrow from their partner when possible, and this borrowing is very harmful.

Surprisingly, the direct evidence is less clear about how harmful it is for the group that the first player is allowed to borrow from the second player. In our main study players in a group with common time budget (JS) performed slightly better than groups with individual time budget (IS), although the difference was not significant. Players with a virtual partner (VSP), however, performed much worse. Differences in how much first players in JS and VSP borrowed from their partner cannot fully explain the difference in performance. There is however, a large difference in how much they borrow in the first four rounds of the game. A large difference in borrowing at the start of the game, but only small difference in how much they take from their partner, indicates better management of their own time. This finding is consistent with a claim in the literature that groups have better selfcontrol. Because we had not preregistered any hypothesis about this, we went on to study this effect in studies where the hypothesis was pre-registered.

The results from these follow-up studies are unclear. The first follow-up study (on MTurk) did not reproduce the large differences in early borrowing between 
players with a virtual second player or a real partner. However, a message on the MTurk message board may have corrupted the results. Thus, we ran the follow-up study again on a Norwegian sample. Here, we find that those with a real partner perform better, but the difference is only weakly significant. Those with a real partner also borrow less in the first four rounds, but the difference is not significant.

We are thus left with a mixed conclusion. Tunneling is harmful for cooperation with a joint time budget, but there seem to be some counteracting effect. This may be due improved self-control with a real partner, but the results are not significant.

In this context, it is worth highlighting that the participants who share a time budget cannot interact or communicate. Any effects of "being in a group" can be ascribed to the mere presence of the co-player in the minds of the participants. It would be remarkable if this was sufficient to induce a strong effect on self-control, as indicated in the first study. A plausible effect would be much smaller and harder to detect.

At the same time, running this as an online experiment causes a lot of noise. For example, a participant that gets a phone call or looses internet connection and thus drops out of the study in a given round will appear as if she borrows a lot in that round. As discussed above, two participants in the first Norwegian study did drop out in the second round and both were in the same treatment. Removing these two observations would give significant results in the direction predicted. With a possibly weak effect and much noise, it is better to leave the question about the effect of group on self-control to future research in a setting with less noise.

That said, the core of our experimental design, sequential work under time pressure, is a relevant feature of many real-world production processes. Investigating the role of self-control in group collaboration and disentangling the role of observability from pro-social motivations could add a new angle to the literature on the effect of being in a group on productivity (Falk and Ichino 2006; Herbst and Mas 2015; van Veldhuizen et al. 2018). Clearly, keeping self-control under pressure is a virtue with potentially far-reaching consequences (Heller et al. 2017; Schilbach 2019). Obtaining a better understanding of how exactly groups, as basic units of human organization, may support self-control is the task of future work.

\section{Appendix}

\section{Data availability and statistical methods}

For data, experimental instructions, and code for reproducing the presented results, see the AWI Experimental Economics data repository at https://doi.org/10.11588/ data/QWSS8L.

We used the software R (version 3.5.3) for all statistical analysis. Given the sample size of more than 100 observations per treatment leg, we used parametric t-tests throughout (all p-values are from two-sided tests). We used the R-packages "effsize" Torchiano (2018) to calculate the effect size (Cohen's d). For all analysis of the time transfers from one round to the next, we clustered standard errors at the individual levels, using the package "plm" Millo (2017) and for the calculation of 
the corresponding effect sizes we followed the steps outlined in Hedges (2007). Given that our response variables were approximately continuous, we used linear regressions, and we follow the steps outlined in Hayes (2013) for the mediation analysis.

\section{Scarcity versus abundance}

Unsurprisingly, performance under scarcity (15 s per question) is lower than performance under abundance (50 s per question). As shown in Fig. 1a in the main text, players score, on average, 46.2 points $(s d=7.3)$ and 48.5 points $(s d=7.8)$ in the individual and joint abundant treatments, respectively. Under scarcity, players score, on average, 26 points $(\mathrm{sd}=6.0)$ in the IS treatment, and less in the two other treatments. The differences between the respective abundance and scarcity treatments are large and strongly significant in all cases (Cohen's $d>3$, $p<0.001$ for all comparisons). That subjects score twice as much under abundance shows that time is really scarce with only 15 s per question.

Figure $1 b$ in the main text shows the drastically different time management induced by scarcity. While players transfer, on average, a positive amount from one round to the next under abundance, players borrow from future rounds (and potentially from their real or virtual partner) under scarcity. Under abundance, players transfer, on average, $5.4 \mathrm{~s}(\mathrm{sd}=28.2)$ from one round to the next in the IA treatment (the green leftmost bar in Fig. 1b). Similarly, players in groups (JA treatment) transfer, on average, $2.8 \mathrm{~s}(\mathrm{sd}=32.4)$ from one round to the next (the second bar from the left in Fig. 1b). Under scarcity, players do not transfer positive, but negative amounts (they borrow). On average, players in the IS treatment borrow $6.6 \mathrm{~s}$ per round $(\mathrm{sd}=14.5)$. When being able to take time from their partner (in the JS treatment), players borrow $9.2 \mathrm{~s}$ per round $(\mathrm{sd}=16.9)$ from future rounds. In the VSP treatment, $13.8 \mathrm{~s}$ are borrowed per round on average $(\mathrm{sd}=27.6)$. Again, the differences between the respective abundance and scarcity treatments are strongly significant in all cases ( $p<0.001$ for all comparisons) and effect sizes are moderate to large ( $d=0.85$ for IA vs. IS, $d=0.64$ for JA vs. JS, and $d=1.19$ for IA vs. VSP).

\section{Supplementary analysis}

See Tables 5 and 6 
Table 5 OLS regression results for the Oslo student sample, parallel to the regression model presented in Table 2 of the main text

\begin{tabular}{llll}
\hline & \multicolumn{2}{l}{ Dependent variable } & \\
\cline { 2 - 4 } & Borrowing & Performance & $(3)$ \\
\cline { 2 - 4 } & $(1)$ & $(2)$ & $0.701(0.577)$ \\
Group & $-8.368(7.148)$ & $1.652^{*}(0.994)$ & $-0.114^{* * *}(0.006)$ \\
Borrowing & & & $-0.582(0.582)$ \\
Female & $11.351(7.176)$ & $-1.872^{*}(0.998)$ & $0.322(0.612)$ \\
KnowFF & $-17.102^{* *}(7.485)$ & $2.265^{* *}(1.041)$ & $0.047(0.061)$ \\
Age & $0.474(0.754)$ & $-0.007(0.105)$ & $25.348^{* * *}(1.655)$ \\
Constant & $54.230^{* * *}(20.138)$ & $19.187^{* * *}(2.801)$ & 172 \\
Observations & 172 & 172 & 0.678 \\
Adjusted $\mathrm{R}^{2}$ & 0.030 & 0.038 & 3.742 \\
Residual std. error & 46.513 & 6.469 & $73.006^{* * *}$ \\
F statistic & $2.321^{*}$ & $2.681^{* *}$ & \\
\hline
\end{tabular}

$* p<0.1 ; * * p<0.05 ; * * * p<0.01$

Table 6 Cox proportional hazards model: coefficient estimates for staying in a given round (hazard ratio $=\exp (\beta)$, such that a positive coefficient implies a larger chance of ending a given round and moving to the next)

\begin{tabular}{lll}
\hline & \multicolumn{2}{l}{ Dependent variable } \\
\cline { 2 - 3 } & \multicolumn{2}{l}{ Time spent in round } \\
\cline { 2 - 3 } & Main study & Follow-up Oslo \\
\hline Group & $0.296^{* * *}(0.043)$ & $0.133^{* * *}(0.049)$ \\
Score & $-0.242^{* * *}(0.020)$ & $-0.271^{* * *}(0.026)$ \\
Age & $-0.009^{* * *}(0.002)$ & $-0.005(0.005)$ \\
Female & $-0.179^{* * *}(0.043)$ & $-0.172^{* * *}(0.049)$ \\
KnowFF & $0.373^{* * *}(0.087)$ & $0.159^{* * *}(0.051)$ \\
Observations & 2243 & 1688 \\
$\mathrm{R}^{2}$ & 0.101 & 0.081 \\
LR test $(d f=5)$ & $237.765^{* * *}$ & $143.320^{* * *}$ \\
\hline
\end{tabular}

$* p<0.1 ; * * p<0.05 ; * * * p<0.01$

\section{Instructions}

\section{Practice round}

Thank you for participating. In what follows, you will play rounds from the game show Family Feud. In each round, you will guess the most popular responses to survey questions (e.g., "Name things to take on a picnic").

For each correct response, you earn a point. Each point provides an entry into a lottery for a $\$ 25$ bonus. The more points you earn, the better your chances of winning. There will be one winner for every 500 tickets. 
IA and IS You will be matched with a partner for the game. You and your treatment: partner will answer separately, but you will earn the same number of lottery tickets. This means that each point that you, or your partner, earns increases the number of tickets that both of you have.

JA and JS You will be matched with a partner for the game. You and your treatment: partner will answer separately, but you will earn the same number of lottery tickets. This means that each point that you, or your partner, earns increases the number of tickets that both of you have. You will also have a joint time budget.

VSP treatment: You will be matched with a virtual player (a computer) for the game, with whom you share a joint time budget. The number of lottery tickets you get will depend on the points you earn, plus the points from the virtual player. How many points you get from the virtual player depends on how much time you leave behind. Each second that you leave behind increases your points according to the average performance of 100 human players that have played this game before.

On the panel to the right, there will be an indication of which round you are in and of how many points you have earned so far. You will also see the time remaining for the current round. (As you can see, this information is already listed for the first practice round.)

Before you begin the game sessions, you will complete a practice session of 3 rounds for which you will have $90 \mathrm{~s}$. The practice session will end when you finish all 3 rounds or exhaust the total time given, whichever comes first. The practice points will not count towards lottery entries.

The amount of time that each round starts with depends on how much total time you have left. The total time will be divided evenly among the remaining rounds. For example, since you currently have $90 \mathrm{~s}$ and 3 rounds to complete, the first round will start with $15 \mathrm{~s}$. No round will ever start with more than $15 \mathrm{~s}$, but rounds can start with less.

IA and IS After the initial time for a round elapses, you will begin to borrow treatment time from future rounds. Each second (beyond the initial time given) (both spent on a round will subtract $2 \mathrm{~s}$ from your remaining total time. In players): the lower right of the panel, you can see a counter of your total time remaining.

After the initial $12 \mathrm{~s}$ of each round, the 'Next Round' button will become active and you can click that button to move on to the next round. Time that you have not spent can be used for future rounds. Following each round, you will be shown the answers. To begin the practice session, please click here. 
JA and JS After the initial time for a round elapses, you will begin to borrow treatment time from future rounds. Each second (beyond the initial time given) (first spent on a round will subtract $2 \mathrm{~s}$ from your remaining total time. In players): the lower right of the panel, you can see a counter of your total time remaining. Once your time budget has been used up, you begin to borrow time from your partner. Each second that you then spend on a round will subtract $2 \mathrm{~s}$ from the time budget of your partner.

After the initial $12 \mathrm{~s}$ of each round, the 'Next Round' button will become active and you can click that button to move on to the next round. Time that you have not spent can be used for future rounds. Time remaining after the last question is transferred to your partner. Following each round, you will be shown the answers. To begin the practice session, please click here.

JA and JS After the initial time for a round elapses, you will begin to borrow treatment time from future rounds. Each second (beyond the initial time given) (second spent on a round will subtract $2 \mathrm{~s}$ from your remaining total time. In players): the lower right of the panel, you can see a counter of your total time remaining. Your initial time budget depends on how much your partner has borrowed from you or transferred to you.

After the initial $12 \mathrm{~s}$ of each round, the 'Next Round' button will become active and you can click that button to move on to the next round. Time that you have not spent can be used for future rounds. Following each round, you will be shown the answers. To begin the practice session, please click here.

VSP After the initial time for a round elapses, you will begin to borrow treatment: time from future rounds. Each second (beyond the initial time given) spent on a round will subtract $2 \mathrm{~s}$ from your remaining total time. In the lower right of the panel, you can see a counter of the total time remaining. Once your time budget has been used up, you begin to borrow time from the virtual second player. Each second that you then spend on a round will subtract $2 \mathrm{~s}$ from the time budget of the virtual second player.

After the initial $12 \mathrm{~s}$ of each round, the 'Next Round' button will become active and you can click that button to move on to the next round. Time that you have not spent can be used for future rounds. Following each round, you will be shown the answers. To begin the practice session, please click here.

\section{Questionnaire about game mechanics}

The following questions are multiple choice with the correct answer (here in boldfaced) being enforced before the player can move on. The questions depend player role and treatment: 
Question 1 (all):

Question 2 (all):

Question 3 (all except VSP):

Question 4 (all):

Question 5 for all players in IA, IS, and VSP, and for second players in JA and JS:

Question 5 for first players in JA and JS:

Question 6 for first players in JA and JS:

Question 6 for the player in VSP and JS:
By entering a correct answer, I get: 1 point / 2 points/5 points

I have to get all five answers right before I can move on: Yes / No

When I earn a point, this is: Better for me than for my partner / As good for me as for my partner. / Better for my partner than for me.

When I borrow time, this means that my time budget... drops by exactly 1 s for every second I use. / drops by 2 s for every second I use. / drops by $5 \mathrm{~s}$ for every second I use.

When I go to the next round before the time for the current round is used up... the unused time is lost / the unused time is added to my remaining time budget / twice the unused time is added to my time budget.

When I go to the next round before the time for the current round is used up... the unused time is lost / the unused time is added to the remaining time budget of my partner and me. / twice the unused time is added to the remaining time budget of my partner and me.

When I borrow time from my partner... this leaves his/her time budget unchanged / this reduces his/her time budget by 2 s for every second I borrow.

Question 6 for second players in JA My initial time budget... is independent

of my partner?s time use / is lower than normal when my partner borrowed from me and is higher when my partner transferred time to me.

When I borrow time from my virtual partner... this reduces the points I get as, on average, players have earned less point the less time they had. I this has no consequence as the virtual partner is a computer./this increases the points I get as, on average, players have earned more point the less time they had. 


\section{Instructions game}

In a moment you will begin the game session where points will earn you actual entries into the lottery for the bonus. For the most part, this game will follow the same rules as in the practice session. Unlike the practice session, the game will consist of 12 rounds. The game will end when you finish all 12 rounds or if you exhaust the total time given.

As a reminder: The amount of time that each round starts with equals total time left divided evenly among the remaining rounds. For example, since you have 600 [180] s and 12 rounds to complete, the first round will start with 50 [15] s. No round will ever start with more than 50 [15] s, but rounds can start with less.

Now comes a paragraph that will differ, depending on the treatment and player

IA and IS treatment (both players):

After the initial time for a round elapses, you will begin to borrow time from future rounds. Each second (beyond the initial time given) spent on a round will subtract $2 \mathrm{~s}$ from your remaining total time. In the lower right, you can see a counter of your total time remaining.

JA and JS treatment After the initial time for a round elapses, you will begin (first players): to borrow time from future rounds. Each second (beyond the initial time given) spent on a round will subtract $2 \mathrm{~s}$ from your remaining total time. In the lower right, you can see a counter of your total time remaining. Once your time budget has been used up, you begin to borrow time from your partner. Each second that you then spend on a round will subtract $2 \mathrm{~s}$ from your partner?s time budget.

JA and JS treatment After the initial time for a round elapses, you will begin (second players): to borrow time from future rounds. Each second (beyond the initial time given) spent on a round will subtract $2 \mathrm{~s}$ from your remaining total time. In the lower right, you can see a counter of your total time remaining. Your initial time budget depends on how much your partner has borrowed from you or transferred to you.

\section{VSP treatment:}

After the initial time for a round elapses, you will begin to borrow time from future rounds. Each second (beyond the initial time given) spent on a round will subtract $2 \mathrm{~s}$ from your remaining total time. In the lower right, you can see a counter of the total time remaining. Once your time budget has been used up, you begin to borrow time from the virtual second player. Each second that you then spend on a round will subtract $2 \mathrm{~s}$ from the time budget of the virtual second player. 
After the initial 20 [6] seconds of each round, the 'Next Round' button will become active and you can click that button to move on to the next round. Following each round, you will be shown the answers.

Remember, your goal is to earn as many points as you can (which will give you a better chance of winning the bonus). Good luck! To begin the game, please click here.

\section{Post-experiment questionnaire}

With the post-experiment questionnaire we seek to obtain a number of demographic variables to get more precise estimates as well as the measures of social preferences and confidence used in hypothesis 7 and 8 . Specifically, we ask these questions (response options are in italic).

1. Highest level of education: not completed Highschool/Highschool/Some College/Bachelor or equivalent/Master or equivalent/PhD or equivalent.

2. Which is your mother tongue: English/Spanish/Chinese/French/Hindi/other

3. Gender: male/female

4. Age: Open field to fill in values from 18-99

5. How many points did you score (on average) per question? 1/2/3/4/5

6. How many points did an average subject score per question? You get an additional 5 points if your answer is correct. 1/2/3/4/5

7. Life sometimes confronts us with difficult/uneasy choices. Imagine that you are hungry in a supermarket in a foreign city, but you are out of cash. Is it OK to take food without paying? Answer on this scale from 1 (it is never OK) to 5 (it is usually OK). 1/2/3/4/5

8. In case you have borrowed from the second player, why did you do so (choose one of the options): I was caught up in the game/I did not think about the second player/I did not understand/I am the better player/none of the above.

9. In case you have transferred time to the second player, why did you do so (choose one of the options): I did not think about the second player/I did not understand/The other player is better than/I wanted to relief the other player from stress/none of the above.

10. Do you like to watch game shows? yes/no

11. Did you know "Family Feud"? yes/no

\section{Screenshots}

Figures 7, 8 and 9 show the screen displayed to the participants. The main frame contains the question, a field to enter an answer, and uncovered correct answers.

The right margin shows the current round number, the players' total score so far, and-importantly - a counter of the remaining time to answer this round's question as well as their total remaining time budget (and the partner's remaining time budget in the relevant treatments). When the time for the current question is used up, the counter turns red and players are warned "You're borrowing time" (see 
Fig. 8). Once the first player's own time budget is used up, the colour of the counter changes and she is now warned that "You're borrowing time from your partner!" (see Fig. 9). Upon pressing the "Next round" button, players receive feedback where the five correct answers are shown in the main frame (for about $4 \mathrm{~s}$, the round number, remaining time and total score are still shown on the right margin). Players are now supposedly out of the "tunnel", and if they discover that they have used all their time and have started borrowing from their partner, they can decide to stop borrowing by simply pressing "Next round" immediately on all remaining questions.

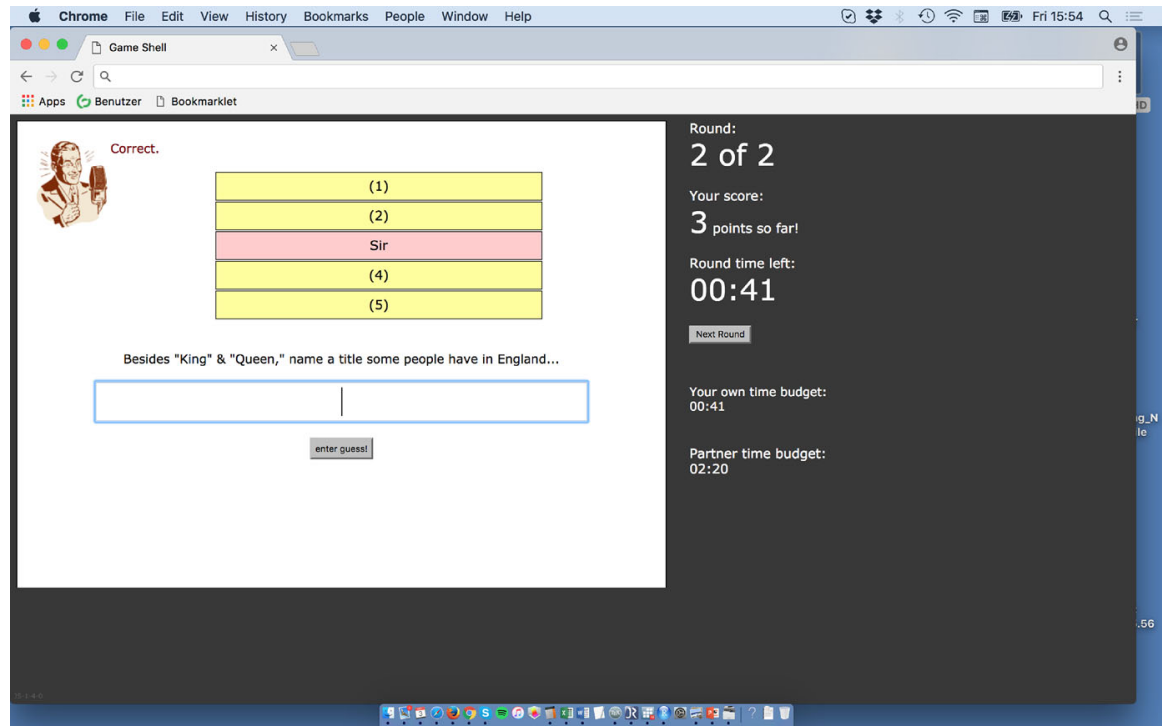

Fig. 7 Screenshot; correct guess 
- Chrome File Edit View History Bookmarks People Window Help

(ㄱ)

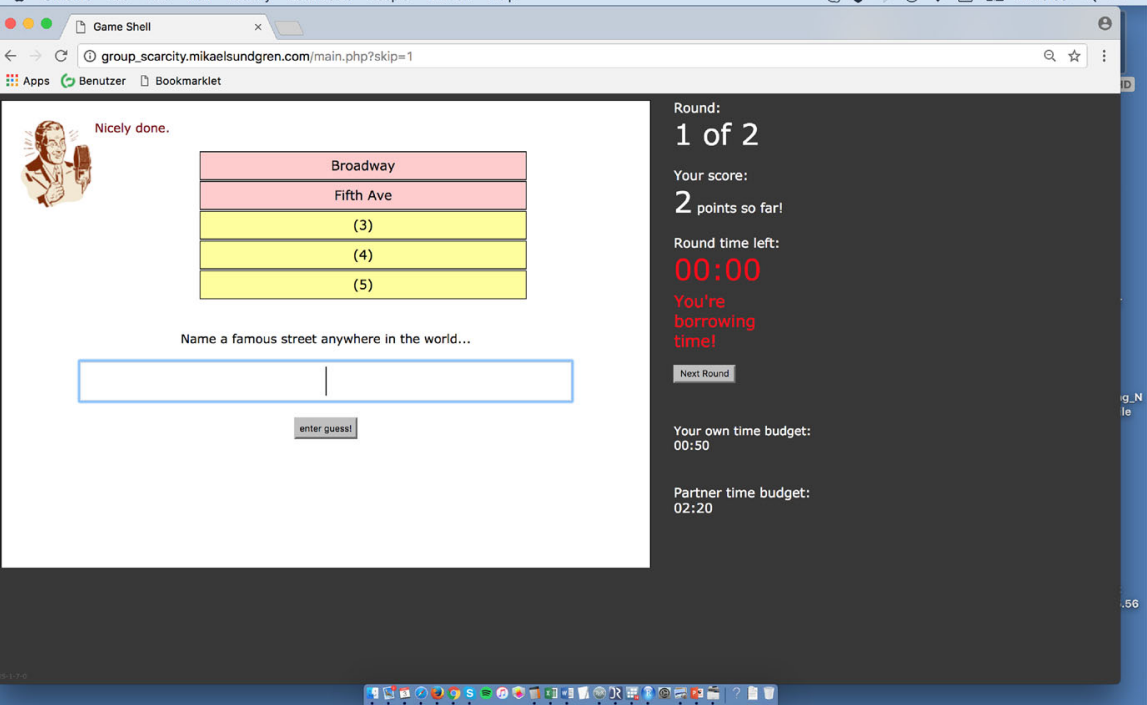

Fig. 8 Screenshot; borrowing time

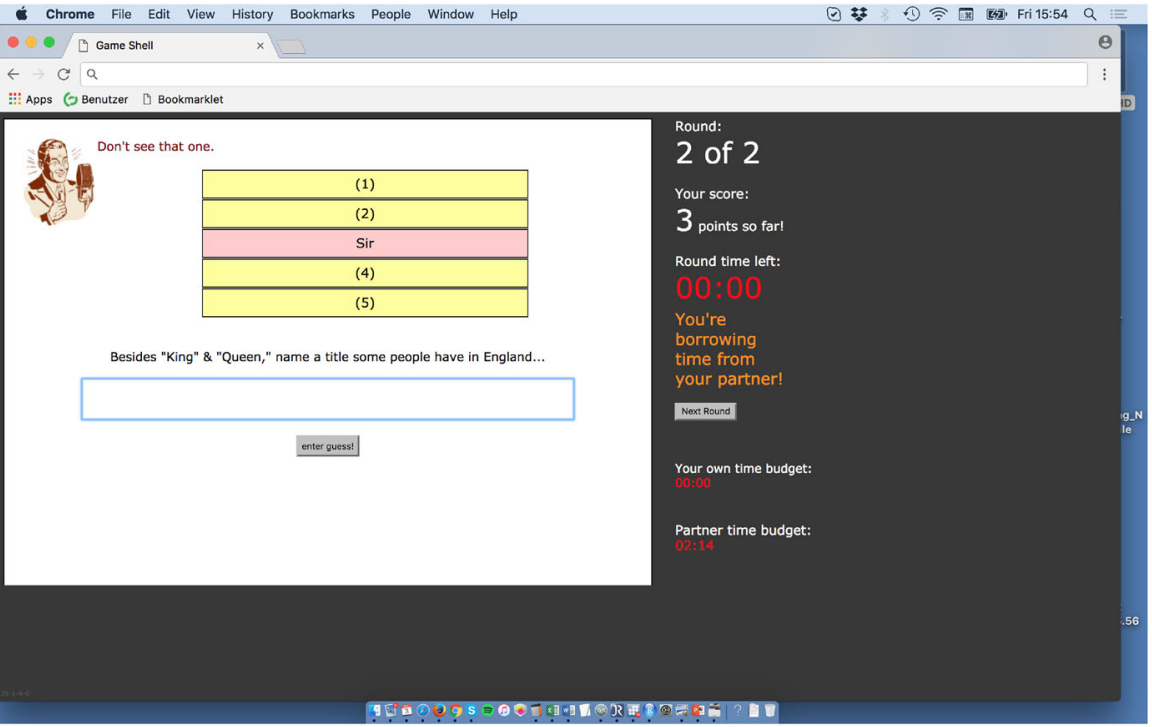

Fig. 9 Screenshot; borrowing time from partner

Acknowledgements We thank Anuj Shah for providing us with the source codes of the original experiment and Mikael Sundgren and Magdalena Peter for programming work and research assistance. This research has been funded by the European Research Council Project NATCOOP (ERC StGr 678049) and by the Norwegian Research Council Project FISHCOM (NFR-280467).

Funding Open access funding provided by University of Oslo (incl Oslo University Hospital). 


\section{Declarations}

Conflict of interest The authors declare that they have no conflict of interest.

Open Access This article is licensed under a Creative Commons Attribution 4.0 International License, which permits use, sharing, adaptation, distribution and reproduction in any medium or format, as long as you give appropriate credit to the original author(s) and the source, provide a link to the Creative Commons licence, and indicate if changes were made. The images or other third party material in this article are included in the article's Creative Commons licence, unless indicated otherwise in a credit line to the material. If material is not included in the article's Creative Commons licence and your intended use is not permitted by statutory regulation or exceeds the permitted use, you will need to obtain permission directly from the copyright holder. To view a copy of this licence, visit http:// creativecommons.org/licenses/by/4.0/.

\section{References}

Bouwmeester, S., Verkoeijen, P. P. J. L., Aczel, B., Barbosa, F., Bègue, L., Brañas-Garza, P., et al. (2017). Registered replication report: Rand, greene, and nowak (2012). Perspectives on Psychological Science, 12(3), 527-542.

Brozyna, C., Guilfoos, T., \& Atlas, S. (2018). Slow and deliberate cooperation in the commons. Nature Sustainability, 1(4), 184-189.

Charness, G., \& Sutter, M. (2012). Groups make better self-interested decisions. Journal of Economic Perspectives, 26(3), 157-76.

Falk, A., \& Ichino, A. (2006). Clean evidence on peer effects. Journal of Labor Economics, 24(1), 39-57.

Fehr, D., Fink, G., \& Jack, K. (2019). Poverty, seasonal scarcity and exchange asymmetries. Working Paper 26357, National Bureau of Economic Research.

Gabaix, X. (2019). Chapter 4-behavioral inattention. In Bernheim, B. D., DellaVigna, S., and Laibson, D., editors, Handbook of Behavioral Economics-Foundations and Applications 2, volume 2 of Handbook of Behavioral Economics: Applications and Foundations 1, pages 261 - 343. NorthHolland.

Haushofer, J., \& Fehr, E. (2014). On the psychology of poverty. Science, 344(6186), 862-867.

Hayes, A. F. (2013). Introduction to mediation, moderation, and conditional process analysis. Guilford Press, New York [u.a.].

Hedges, L. V. (2007). Effect sizes in cluster-randomized designs. Journal of Educational and Behavioral Statistics, 32(4), 341-370.

Heller, S. B., Shah, A. K., Guryan, J., Ludwig, J., Mullainathan, S., \& Pollack, H. A. (2017). Thinking, fast and slow? some field experiments to reduce crime and dropout in chicago*. The Quarterly Journal of Economics, 132(1), 1-54.

Herbst, D., \& Mas, A. (2015). Peer effects on worker output in the laboratory generalize to the field. Science, 350(6260), 545-549.

Kugler, T., Kausel, E. E., \& Kocher, M. G. (2012). Are groups more rational than individuals? A review of interactive decision making in groups. Wiley Interdisciplinary Reviews: Cognitive Science, 3(4), 471-482.

Kurtz, J. (2008). Looking to the future to appreciate the present: The benefits of perceived temporal scarcity. Psychological Science, 19(12), 1238-1241.

Laajaj, R. (2017). Endogenous time horizon and behavioral poverty trap: Theory and evidence from mozambique. Journal of Development Economics, 127, 187-208.

Lichand, G. \& Mani, A. (2016). Cognitive Droughts. CAGE Online Working Paper Series 298, Competitive Advantage in the Global Economy (CAGE).

Mani, A., Mullainathan, S., Shafir, E., \& Zhao, J. (2013). Poverty impedes cognitive function. Science, 341(6149), 976-980.

Millo, G. (2017). Robust standard error estimators for panel models: A unifying approach. Journal of Statistical Software, 82(3), 1-27.

Mullainathan, S., \& Shafir, E. (2013). Scarcity: The true cost of not having enough. New York: Penguin.

Piovesan, M., \& Wengström, E. (2009). Fast or fair? A study of response times. Economics Letters, 105(2), 193-196. 
Prediger, S., Vollan, B., \& Herrmann, B. (2014). Resource scarcity and antisocial behavior. Journal of Public Economics, 119, 1-9.

R Core Team. (2019). R: A Language and Environment for Statistical Computing. Vienna, Austria: R Foundation for Statistical Computing.

Rand, D. G. (2016). Cooperation, fast and slow: Meta-analytic evidence for a theory of social heuristics and self-interested deliberation. Psychological Science, 27(9), 1192-1206.

Rand, D. G., Greene, J. D., \& Nowak, M. A. (2012). Spontaneous giving and calculated greed. Nature, 489:427.

Roux, C., Goldsmith, K., \& Bonezzi, A. (2015). On the psychology of scarcity: When reminders of resource scarcity promote selfish (and generous) behavior. Journal of Consumer Research, 42(4), 615-631.

Schilbach, F. (2019). Alcohol and self-control: A field experiment in India. American Economic Review, 109(4), 1290-1322.

Shah, A. K., Mullainathan, S., \& Shafir, E. (2012). Some consequences of having too little. Science, 338(6107), 682-685.

Sims, C. A. (2003). Implications of rational inattention. Journal of Monetary Economics, 50(3), 665-690. Swiss National Bank/Study Center Gerzensee Conference on Monetary Policy under Incomplete Information.

Spears, D. (2011). Economic decision-making in poverty depletes behavioral control. The B.E. Journal of Economic Analysis \& Policy, 11(1).

Spiliopoulos, L., \& Ortmann, A. (2018). The bcd of response time analysis in experimental economics. Experimental Economics, 21(2), 383-433.

Tinghög, G., Andersson, D., Bonn, C., Böttiger, H., Josephson, C., Lundgren, G., Västfjäll, D., Kirchler, M., \& Johannesson, M. (2013). Intuition and cooperation reconsidered. Nature, 498, E1.

Torchiano, M. (2018). effsize: Efficient Effect Size Computation. R package version, 7, 4.

van Veldhuizen, R., Oosterbeek, H., \& Sonnemans, J. (2018). Peers at work: Evidence from the lab. PLOS ONE, 13(2), 1-15.

Publisher's Note Springer Nature remains neutral with regard to jurisdictional claims in published maps and institutional affiliations. 